\title{
Letter to the Editor: Endocrine and metabolic emergencies in children: hypocalcemia, hypoglycemia, adrenal insufficiency, and metabolic acidosis including diabetic ketoacidosis
}

Viktor Rosival, PhD

SYNLAB Department of Laboratory Medicine, Derers Hospital, Bratislava, Slovak
Received: 8 March, 2016

Accepted: 17 June, 2016

Address for correspondence:

Viktor Rosival, PhD

SYNLAB Department of Laboratory Medicine, Dérer's Hospital, Limbová 5, SK-833 01 Bratislava, Slovakia

Tel: +421-335511831

Fax: +421-335511831

E-mail: rosivalv@hotmail.com
In the paper entitled "Endocrine and metabolic emergencies in children: hypocalcemia, hypoglycemia, adrenal insufficiency, and metabolic acidosis including diabetic ketoacidosis ${ }^{\text {") }}$ are some discrepancies with the literature.

First, on page 183, the author writes "Diabetic ketoacidosis usually occurred by absolute/ relative insulin deficiency .... Since the Nobel prize was awarded in 1977 to Rosalyn S Yalow for the development of new methods of biochemical analysis that make it possible to measure insulin concentration in human plasma, these methods have been used worldwide. In 1981, the monograph "Diabetic coma: ketoacidotic and hyperosmolar" was published ${ }^{2}$, and on page 67, Fig. 6.3 has the names of 12 authors who have reported sufficient amounts of plasmatic insulin in patients with diabetic ketoacidosis. In contrast, absolute deficiency of plasmatic insulin has been reported in diabetic patients with hyperglycemic hyperosmolar non ketotic syndrome $^{3)}$, as well as in diabetic patients on routine control without subjective complaints . $^{4}$. Where are published concrete reports on deficiency of plasmatic insulin in patients with diabetic ketoacidosis? What is the "safe level" of plasmatic insulin concentration that makes development of diabetic ketoacidosis impossible?

Second, on page 184, the author writes "... bicarbonate therapy may be unnecessary and may actually be harmfuI". However, on his page 183 he writes "Acidemia ... results in CNS dysfunction ... manifested as altered level of consciousness progressing to coma ... and even death .... This is explained with the inactivation of the glycolytic enzyme phosphofructokinase by low blood-pH and the ensuing impaired utilisation of glucose ${ }^{5}$. Therefore, increase of the low blood-pH after infusions of sodium bicarbonate is in comatose patients life-saving, lethality of coma with this treatment is zero $/ \mathrm{e} \mathrm{g} /{ }^{6}$. Where are published reports on zero lethality of coma in diabetic ketoacidosis without alkalising solutions? Where are published results of the treatment recommended by the author?

\section{Conflict of interest}

No potential conflict of interest relevant to this article was reported.

\section{References}

1. Kim SY. Endocrine and metabolic emergencies in children: hypocalcemia, hypoglycemia, adrenal insufficiency, and metabolic acidosis including diabetic ketoacidosis. Ann Pediatr Endocrinol Metab 2015;20:179-86.

2. Schade DS, Eaton RP, Alberti KGMM, Johnston DO. Dtabetic coma:ketoacidotic and hyperosmolar. Albuquerque: University of New Mexico Press, 1981.

3. Vinik A, Seftel H, Joffe BI. Metabolic findings in hyperosmolar, non-ketotic diabetic stupor. Lancet 1970;2:797-9. 
4. Matsuyama T, Hoffman WH, Dunbar JC, Foà NL, Foà PP. Glucose, insulin, pancreatic glucagon and glucagon-like immunoreactive materials in the plasma of normal and diabetic children. Effect of the initial insulin treatment. Horm Metab Res 1975;7:452-6.

5. Nyenwe EA, Razavi LN, Kitabchi AE, Khan AN, Wan JY.
Acidosis: the prime determinant of depressed sensorium in diabetic ketoacidosis. Diabetes Care 2010;33:1837-9.

6. Yordam N, Gonc EN, Kandemir N, Alikasifoglu A, Ozon A. Ten-year experience in management of diabetic ketoacidosis and ketosis: 140 episodes at pediatric age. Turk J Pediatr 2005;47:334-8. 